The Decisions of Entrepreneurs

and Their Agents: Revealed

Levels of Risk Aversion and

Betrayal Aversion

Faculty Research Working Paper Series

\title{
Anna Dreber
}

Stockholm School of Economics

David Rand

Harvard University and Yale University

Nils Wernerfelt

Massachusetts Institute of Technology

Peter Worrell

The Bigelow Company

Richard Zeckhauser

Harvard Kennedy School

\section{May 2013}

\section{RWP13-016}

Visit the HKS Faculty Research Working Paper series at:

http://web.hks.harvard.edu/publications

The views expressed in the HKS Faculty Research Working Paper Series are those of the author(s) and do not necessarily reflect those of the John F. Kennedy School of Government or of Harvard University. Faculty Research Working Papers have not undergone formal review and approval. Such papers are included in this series to elicit feedback and to encourage debate on important public policy challenges. Copyright belongs to the author(s). Papers may be downloaded for personal use only. 


\title{
The Decisions of Entrepreneurs and Their Agents:
}

\section{Revealed Levels of Risk Aversion and Betrayal Aversion}

\author{
Anna Dreber ${ }^{1}$, David Rand ${ }^{2,3}$, Nils Wernerfelt ${ }^{4}$, Peter Worrell ${ }^{5}$ and Richard \\ Zeckhauser $^{6}$ \\ ${ }^{1}$ Department of Economics, Stockholm School of Economics, Stockholm Sweden \\ ${ }^{2}$ Program for Evolutionary Dynamics, Harvard University, Cambridge MA USA \\ ${ }^{3}$ Department of Psychology, Yale University, New Haven CT USA \\ ${ }^{4}$ Department of Economics, Massachusetts Institute of Technology, Cambridge MA USA \\ ${ }^{5}$ The Bigelow Company, Portsmouth NH USA \\ ${ }^{6}$ Harvard Kennedy School, Harvard University, Cambridge MA
}

\begin{abstract}
This paper studies decision making by successful entrepreneurs and their agents. Since entrepreneurs decisions are often influenced by their agents' advice, understanding the behavior of both involved parties is crucial in analyzing observed decisions. To this end, a sample of successful American entrepreneurs and their agents made a high-stakes decision in a real-world context, albeit in an experimental setting offering experimentalscale payoffs. They were asked whether to accept a contract in what was essentially a trust game. A monetary gamble measured economic risk taking; and the difference between the two measured betrayal aversion. All entrepreneurs assumed the professional role as principal. All individuals playing agent were real world agents. We also have some agents play the role of the principal, and thus test whether subjects' roles affect the decisions they make.

Consistent with most prior studies, our subjects proved both economically risk-averse and betrayal averse. Little difference in behavior emerged between entrepreneurs and agents in their respective professional capacities, or with agents acting as principals. These results imply that, under our realistically framed business scenario with aligned incentives, agents could be relied upon to be "faithful," to act according to their principals' proclivities. Importantly, however, they do not advise against what many expert observers believe to be principals' excess aversion to risks. That is, they fail to act as "correcting agents."
\end{abstract}




\section{Introduction}

Entrepreneurial decision making has long been recognized as an important object of study. Much previous research has focused on whether entrepreneurs differ from the population at large. For example, entrepreneurs have long been hypothesized to be willing and effective risk takers compared to the general population. (The classic works are Knight 1921 and Schumpeter 1934, with recent support from Stewart and Roth 2001 and Hvide and Panos 2012.) Other studies cast doubt upon this claim (e.g., Brockhaus 1980; Shane 2003; Wu and Knott 2006; Holm et al. 2013).

Few entrepreneurs makes high-stakes decisions without consulting their lawyers, accountants, consultants, etc. If such decisions are undertaken in consultation with their agents, then the risk preferences of the agents can influence the ultimate decisions of entrepreneurs. The current study thus explores the risk preferences of actual seasoned, successful entrepreneurs, i.e., owner-managers of private businesses with significant enterprise value, and compares them to those of their professional expert advisors (lawyers, accountants, commercial bankers, wealth managers, and other consultants). Building off past work, we seek to shed light on the decision making of entrepreneurs and their agents in scenarios involving economic and social risk, and the potential for betrayal.

We now discuss various features of the risks we study. Most experiments on risk taking involve choices among desiccated lotteries, situations characterized solely by dollar payoffs and the probabilities with which they will be received. A chance device, such as the drawing of a ball from an urn, determines the outcome. This is straight economic risk taking, where there is nonstrategic uncertainty (following the terminology of Holm et al. 2013).

Most risk-taking decisions by entrepreneurs differ dramatically from these "laboratory" decisions in two important respects: (1) they address a real-world situation in which the payoffs and probabilities are embedded in a context; and (2) they involve some reliance on other individuals. These two properties are present when a manager is hired, when a contract is undertaken with another corporation, when a company is bought or sold, or 
when a new product is developed. The manager, the executives of the other corporation, and the development team are all real and play major roles in determining the outcome.

Whenever an outcome is determined by another individual, we refer to it as a social risk and the type of uncertainty is thus strategic (again following the terminology of Holm et al. 2013). The decision maker is seeking risky gains, which will be reaped if and only if another person follows the norm of rewarding trust, and thus behaves as hoped. Social risk taking has been shown to differ from economic risk taking (Bohnet and Zeckhauser 2004). Most importantly, across a variety of contexts, individuals have proved to be much more willing to accept a risk that depends on the actions of "nature," that is, a chance device, than a risk involving identical probabilities and payoffs, but that depends on the actions of another individual.

Social risk taking is well illustrated in the famed trust game (TG) (Berg, Dickhaut, and McCabe 1995). In the TG, one person (Player 1) chooses how much money to send to another person (Player 2). Any money that is sent gets multiplied by a factor greater than 1 (capturing the potential gains from trust). Player 2 subsequently chooses an amount of money to return to Player 1. That amount, which is not multiplied, reflects Player 2's trustworthiness. Trusting someone in such a trust game is a risky investment. If the trustee proves trustworthy, then the trustor earns a profit; but the trustee can simply keep more money, producing a loss for the trustor.

Studies have been conducted comparing Player 1's behavior in a TG where Player 2's decision is made by a human subject to a game with the same payoffs where "nature" (a chance device) makes that decision. They have found that people are substantially less risk-taking when another individual rather than nature determines the outcome. The additional factor is referred to as betrayal aversion: the potential costs involved in social risk taking are deemed greater than the mere monetary losses to be incurred in the case of an untrustworthy Player 2 (Bohnet and Zeckhauser 2004; Bohnet et al. 2008; and Bohnet et al. 2010). ${ }^{1}$

\footnotetext{
${ }^{1}$ This is a within-subject study. Bohnet and Zeckhauser (2004) define betrayal aversion as the difference in behavior between a trust game and a risky dictator game (where the lottery has a third party that benefits from the principal's risk taking). We do not include such a risky dictator game because Bohnet and Zeckhauser (2004) do not find a substantial effect from this type of social preferences, but this means that
} 
This study addresses two major questions. The first question is whether entrepreneurs and their agents behave similar to one another in terms of both risk preferences and betrayal aversion. We focus on betrayal aversion and study to what extent it plays a role among these individuals, particularly when they are making a defined business decision of the type such individuals confront every day. ${ }^{2}$ Thus, within such a population, we explore both economic risk taking and social risk taking. Do these subjects, who have extensive professional experience with risk-taking, show the same tendencies observed among less experienced--and generally less successful--subjects? Given our focus on the real world, we start by noting that most important business decisions involve two parties: principals, those responsible for the decision (and who will suffer/enjoy the consequences of its outcome), and individuals in the professional role of expert advisor, whom we refer to as agents. When entrepreneurs are making decisions, their agents include lawyers, accountants, commercial bankers, and consultants. In theory, these agents are supposed to represent their entrepreneur/principals faithfully, at least as long as the incentives are aligned, but are expected to be coldly objective (Stiglitz 1987). Agents presumably have more experience with big deals than their principals, since they are called in on big deals on a regular basis. Agents are expected bring in their domain expertise that comes from both training and experience and recommend decisions to their entrepreneur clients, based on what is in their experience, their client's best interest. Since entrepreneurs/principals may be unaware of their potential biases, or have difficulty combating them, there is thus potential for agents to suggest ways in which outcomes can be improved. The difference between entrepreneurs and agents in terms of experience making or recommending risky decisions leads us to conjecture that these two groups of individuals might behave differently in our games.

Our second major question is whether subjects' roles affect the decisions they make. There are two elements to a subject's role: what is his profession in real life, and what is his assignment in the decision making task. Our real life PRINCIPALS only are assigned

our format does not eliminate the potential that social preferences played a role in what we define as betrayal aversion.

${ }^{2}$ For example, the strategic uncertainty regarding the behavior of another individual that is captured by the trust game is also present in many business decisions. Our game (as described later) actually is even more explicit than the standard trust game about the nature of the relationship between the actors, since we have a clear indication of trust, whereas it normally can only be inferred. 
to the role of principals. However, our real life AGENTS are randomly assigned to play the role of a principal or an agent. For expository clarity, when we capitalize either PRINCIPAL(S) or AGENT(S), we are referring to subjects in their real-world roles and not their experimental roles. Thus, we examine whether risk taking differs depending on one's real-life profession and one's assigned role. Also important, we embed the main decision task in a business context that should be familiar to our subjects, as opposed to the typical lottery questions that inform so much economic and psychological research.

We start out comparing decision making under nonstrategic and strategic uncertainty, i.e., economic and social risk taking, and replicate the common finding that people are betrayal-averse. In our remaining experiments, we explore betrayal aversion and economic risk taking, where the decision maker is acting as either a principal or a principal's agent. We find little difference in behavior across conditions. This shows that the AGENTS in our experiment are "faithful agents"; they behave similarly when acting either for themselves or for someone else, and in both cases act similarly to PRINCIPALS.

The theoretical principal-agent literature suggests that efficiency losses can occur if the principals and their agents differ in their risk preferences (Grossman and Hart 1983). Previous studies have shown that, when people make choices on behalf of others in the domain of economic risk taking, they use a combination of their own risk preferences and their estimates of the risk preferences of those they represent. This often inclines them toward risk neutrality (Daruvala 2007). People making economic risk-taking decisions for an anonymous stranger are less risk-averse than when making decisions on behalf of themselves (Chakravarty et al. 2009). We wished to determine whether such behavior would persist in the unstudied domain of social risk taking. Under both settings in our sample, there proved to be reasonable concordance between the decision making of principals and agents. That is, we find that real-world AGENTS, acting on behalf of principals in a simulated traditional business context, recommend decisions that reflect levels of risk aversion and betrayal aversion consistent with those of their principals. It appears that they understand their principals' preferences, and that they are faithful. This might pose problems if for example, their principals are adversely affected by cognitive biases in decision making leading them to make less than optimal decisions (in this case 
to be overly risk or betrayal averse). Thus a less positive interpretation of agent fidelity is that they are not acting as objective expert advisors, but simply reflecting or worse purposefully reproducing the biases of their PRINCIPALS.

This study is the first to test social risk taking and betrayal aversion in a realistic business scenario, one where participants are accustomed to making decisions. Some previous studies suggest that people behave differently when asked about a realistic scenario in their arena of expertise, as opposed to a hypothetical scenario far removed from it, or a barebones lottery. (See, for example, Schubert et al. 1999, who compare economic risk taking in an abstract gambling decision with economic risk taking embedded in an investment or insurance context.) We thus expected our subjects, who have extensive business experience, to be less risk-averse in this type of real-world scenario related to business than in a more abstract scenario. Our subjects, however, turn out to be very (and surprisingly) risk-averse in both the economic and the social domains.

There are previous papers comparing entrepreneurs to non-entrepreneurs with experimental measures (e.g., Elston et al. 2005; Macko and Tyszka 2009; Holm et al. 2013). Most related to ours in terms of measures is Holm et al. (2013), who study both economic and social risk taking as we do, as well as ambiguity aversion and competitiveness, in a stratified random sample of entrepreneurs and a control group in China. They find no significant difference in economic risk taking or ambiguity aversion, but that entrepreneurs are more socially risk taking (also measured by the trust game) and more competitive.

Our paper proceeds as follows. In Section 2, we introduce the experimental design and describe the subjects. In Section 3, we present the results. In Section 4, we discuss the results and conclude.

\section{Experimental Design}

A total of 162 subjects participated in this study on social and economic risk taking. Through The Bigelow Company, a company that arranges mergers and acquisitions on behalf of the owners of entrepreneurial companies, we were able to recruit both professional PRINCIPALS and professional AGENTS for our study. (All subjects in our study were clients of The Bigelow Company, potential clients, or advisors to such.) Our 
subjects are either successful entrepreneur owner-managers or AGENTS who advise that same class of owner-managers. These entrepreneur owner-managers are thus aware that the decisions they make as principals often have significant impact on enterprise value, which frequently has taken a lifetime to build (and sometimes lifetimes of previous generations as well). Their agents are similarly aware.

We recruited subjects through email invitations describing our decision making study. Potential subjects were identified from The Bigelow Company's proprietary internal database of professional contacts. A total of 194 PRINCIPALS, 726 AGENTS acting as principals, and 724 AGENTS acting as agents were contacted, with respective response rates of 40 PRINCIPALS, 63 AGENTS acting as principals, and 59 AGENTS acting as agents. ${ }^{3}$ The study was open online for several weeks, and occasional reminder emails were sent to subjects who had not yet replied. All participation was voluntary, and our study received approval from the Harvard Human Subjects Committee.

The trust game was framed in the following business context. One company (called ADC in the instructions) produces a critical component of a product for another company (called Daisy). If nothing changes, each company will make $\$ 10$ million in profit from this project. Daisy (the equivalent of Player 2 in the TG) gives ADC (the equivalent of Player 1) a proposal that entails a risky outcome to be determined by Daisy's choice. Specifically, Daisy proposes that ADC accept an R\&D commission to develop a new version of the product. Daisy creates the expectation, but makes no binding commitment, that it will engage ADC to produce the product. If Daisy follows through and engages ADC for production, the companies will earn $\$ 15$ million each; but if Daisy instead goes to China, a cheaper source for production, ADC will earn only $\$ 8$ million while Daisy earns \$22 million. This situation is illustrated in Figure 1.

\footnotetext{
${ }^{3}$ We note that the response rate for PRINCIPALS was significantly higher than either other category (ttest, $\mathrm{p}<0.01$ for both).
} 
Figure 1. Trust game in business context.

\begin{tabular}{|l|c|c|c|}
\cline { 2 - 3 } \multicolumn{2}{c|}{} & \multicolumn{2}{c|}{ Profits to } \\
\hline $\begin{array}{l}\text { ADC rejects } \\
\text { proposal }\end{array}$ & ADC & Daisy \\
\hline
\end{tabular}

\begin{tabular}{|l|l|c|c|}
\cline { 2 - 4 } \multicolumn{1}{c|}{} & $\begin{array}{l}\text { Daisy production } \\
\text { choice: }\end{array}$ & \multicolumn{2}{c|}{} \\
\hline $\begin{array}{l}\text { ADC accepts } \\
\text { proposal }\end{array}$ & Stick with ADC & \$15 million & \$15 million \\
\cline { 2 - 4 } & Go to China & $\$ 8$ million & \$22 million \\
\hline
\end{tabular}

Each subject made decisions in all three of the following different scenarios.

In Scenario 1, each subject took the role of ADC (Player ONE in a trust game), either as a principal (the CEO of ADC) or as an agent (advisor to the CEO of ADC). Subjects were told that they would be randomly paired with other persons who had been assigned to the role of Daisy (Player TWO). Rather than Player ONEs simply being asked whether they would accept or reject the proposal, subjects were asked to base their decisions to accept on the probability that Player TWOs would choose to remain with ADC (that is, be trustworthy/loyal). In particular, each Player ONE was asked for the minimum percentage of Player TWOs choosing to remain with ADC for which that Player ONE would choose to accept the proposal. Since a Player ONE would be paired at random with a computer-matched Player TWO, this established the "minimum acceptable probability" (MAP) for that Player ONE of Player TWOs who are loyal to ADC.

This system gives the ADC principals and their advisors an incentive to respond honestly, since if they really required percentage $R$, and the true percentage was $Q \geq R$, they would accept the proposal. They would then have at least an $\mathrm{R}$ chance that Daisy would remain loyal to them, and probably a greater chance, since Q was unlikely to be precisely equal to $\mathrm{R}$.

Our experiment had principals decide for themselves. By contrast, agents recommended actions to a hypothetical $\mathrm{CEO}$ of $\mathrm{ADC}$ (a principal), with the understanding that the 
principal would follow the agent's advice. Subjects, whether acting as principals or as agents, were informed that they would receive $\$ 1$ for every $\$ 1$ million earned by ADC.

In Scenario 2, the subjects were placed instead in the role of Daisy (Player TWOs) and paired with other random computer-matched subjects who would act in the role of ADC (Player ONEs). We asked the TWOs whether they would remain loyal to ADC or go to China if Player ONE chose to accept their proposal. Subjects in this TWO role received $\$ 1$ for each $\$ 1$ million earned by Daisy.

In Scenario 3, the subjects participated in an economic risk-taking task. They were shown two alternatives. Alternative A would pay $\$ 100$ with certainty, whereas Alternative B would pay $\$ 150$ with probability $\mathrm{p}$ and $\$ 80$ with probability $1-\mathrm{p}$. We asked the subjects how large $\mathrm{p}$ would have to be for them to choose the lottery in Alternative B instead of the certainty in Alternative A. This is thus an abstract non-social version of Scenario 1, with "nature" rather than another person determining the outcome of Alternative B. Subjects were informed that subsequently 10 participants would be selected at random from all respondents to actually engage in this task for money, with their decisions as to whether or not to gamble based on what they had indicated in the study. They were told that a value of $\mathrm{p}$ would be chosen, and that whether or not they gambled would depend on that value of $\mathrm{p}$. If they did gamble, a random number would be drawn to determine if they had won. ${ }^{4}$

Finally, subjects answered a questionnaire on their professional experiences and demographic characteristics. (See the Appendix for summary statistics.)

Subjects were paid by check, mailed to them following the conclusion of the study. Subjects also received an email describing their results in each scenario.

\section{Results}

\subsection{Economic risk aversion - the gamble}

Subjects, whether PRINCIPALS or AGENTS, were strongly risk-averse. In the risky gamble (Scenario 3), the break-even probability was $2 / 7$ (about 0.29 ), whereas the mean response in our sample was 0.507 , a dramatically higher and more risk-averse value

\footnotetext{
${ }^{4}$ See the instructions included in the Appendix for precise details on what the subjects were told.
} 
(Wilcoxon signed-rank test, ${ }^{5} \mathrm{p}<0.0001$ ). (This extreme difference raises the question as to whether many subjects, despite dealing with uncertain situations every day, even bothered to compute the break-even probability.) Table 1 presents the results. It is interesting to note that Bohnet et al. (2010) used the same measurement in their crossnation study conducted among students, yet the mean among our sample of PRINCIPALS $(0.515, \mathrm{~N}=35)$ and AGENTS $(0.504, \mathrm{~N}=116)$ is higher than the mean that study reports for any country (the highest they report is 0.48 from the United Arab Emirates). Though our stakes were ten times higher for the gamble, this is unlikely to explain the difference, since our subjects - all successful as entrepreneurs or professionals advising them - had incomes many times greater than students. The explanation awaits further study. We suspect it relates to an aversion of entrepreneurs and their advisors to taking gambles over which they have no control. This result could also be due to the fact that we had subjects first play the trust game and then do the economic risk task rather than employ a between-subjects format.

Table 1. Economic risk aversion by condition and background. Mean (standard deviation). ${ }^{6}$

\begin{tabular}{|c|c|c|c|c|}
\hline $\begin{array}{l}\text { PRINCIPALS acting } \\
\text { as Principals }\end{array}$ & $\begin{array}{l}\text { AGENTS acting } \\
\text { as Principals }\end{array}$ & $\begin{array}{l}\text { AGENTS acting } \\
\text { as Agents }\end{array}$ & All AGENTS & All subjects \\
\hline $0.515^{* * *}$ & $0.523^{* * *}$ & $0.485^{* * *}$ & $0.504^{* * *}$ & $0.507^{* * *}$ \\
$(0.260)$ & $(0.244)$ & $(0.225)$ & $(0.235)$ & $(0.240)$ \\
\hline $\mathrm{N}=35$ & $\mathrm{~N}=60$ & $\mathrm{~N}=56$ & $\mathrm{~N}=116$ & $\mathrm{~N}=151$ \\
\hline $\mathrm{p}=.0001$ & $\mathrm{p}=.0001$ & $\mathrm{p}<.0001$ & $\mathrm{p}<.0001$ & $\mathrm{p}<.0001$ \\
\hline
\end{tabular}

*** denotes significantly different from $2 / 7$ at $\mathrm{p}=0.001$.

\subsection{Betrayal aversion}

Our PRINCIPALS and AGENTS both showed substantial betrayal aversion. To measure betrayal aversion, we look at subjects who were playing the role of ADC. We compare their minimum acceptable probabilities of trustworthy Player TWOs in Scenario 1, with

\footnotetext{
${ }^{5}$ All further p-values are two-sided Wilcoxon signed-rank tests, unless stated otherwise.

${ }^{6} \mathrm{We}$ also explored comparing the distributions of reported values of risk aversion and found no differences across conditions.
} 
their MAPs for the lottery in Scenario 3. This comparison procedure follows Bohnet and Zeckhauser (2004). If there were no betrayal aversion, individuals would not care whether "nature" or a decision by an individual led to a bad outcome. Thus, they would select the same MAP in both contexts. However, if our subjects were betrayal-averse, their MAP under the ADC-Daisy scenario would be higher. (Below, we sometimes refer to this as the betrayal scenario.)

Table 2 presents the results. It shows that looking at all subjects together, MAPs in the ADC-Daisy scenario were significantly higher $(\mathrm{p}=0.001)$. Nearly twice as many subjects had a higher value for the Daisy scenario $(\mathrm{N}=81)$ rather than a higher value for the gamble $(\mathrm{N}=42)$. The remaining 27 subjects had equal values for both measures.

It is important to reiterate that the stakes in the gamble were far higher than those in the betrayal scenario. Thus, with stakes raised, risk aversion should have inflated the MAPs in the gamble relative to those in ADC-Daisy. This may well explain the behavior of some of the 42 subjects with higher values for the gamble than for the Daisy scenario. Therefore, given the substantial risk aversion our subjects exhibited, our findings probably underestimate the level of their betrayal aversion.

Table 2. Social risk aversion by condition and background. Mean (standard deviation).

\begin{tabular}{|c|c|c|c|c|}
\hline $\begin{array}{l}\text { PRINCIPALS acting as } \\
\text { Principals }\end{array}$ & $\begin{array}{l}\text { AGENTS acting } \\
\text { as Principals }\end{array}$ & $\begin{array}{l}\text { AGENTS acting } \\
\text { as Agents }\end{array}$ & All AGENTS & All subjects \\
\hline $0.583^{*}$ & $0.583^{*}$ & $0.582^{* * *}$ & $0.583 * *$ & $0.583 * * *$ \\
$(0.263)$ & $(0.257)$ & $(0.271)$ & $(0.263)$ & $(0.262)$ \\
\hline $\mathrm{N}=40$ & $\mathrm{~N}=63$ & $\mathrm{~N}=59$ & $\mathrm{~N}=122$ & $\mathrm{~N}=162$ \\
\hline $\mathrm{p}=.0935$ & $\mathrm{p}=.0503$ & $\mathrm{p}=.0097$ & $\mathrm{p}=.0015$ & $\mathrm{p}=.0004$ \\
\hline
\end{tabular}

\subsection{Faithful agents?}

Here we explore whether there are differences among PRINCIPALS as subjects acting on their own behalf, AGENTS acting as agents on behalf of their principals, ${ }^{7}$ and AGENTS

\footnotetext{
${ }^{7}$ We might expect that agents acting on behalf of principals would make choices that would accord with the choice of the average principal. Such a focus would reduce the standard deviation of their answers.
} 
acting as principals. The pure monetary payoffs were such that preferences were perfectly aligned. However, these were three quite different conditions, and we might expect to find substantial differences among them. Such differences could arise because AGENTS simply had different preferences, because AGENTS tried to dampen their principals' extreme betrayal aversions, or because AGENTS acting as agents chose different actions than AGENTS acting as principals.

In each of our three conditions - AGENTS acting as agents, AGENTS acting as principals, and PRINCIPALS acting as principals - the average response for the ADCDaisy scenario was higher than the average response for the straight gamble (0.582 vs. 0.485 ; 0.582 vs. 0.523 ; and 0.583 vs. 0.515 , respectively). (See Tables 1 and 2.) Not surprisingly, we find significant evidence of betrayal aversion for players in every condition ( $\mathrm{p}=0.017, \mathrm{p}=0.05, \mathrm{p}=0.01$, respectively). The same result holds if we consider AGENTS in both roles jointly ( $\mathrm{p}=0.001$; the mean responses for the ADC-Daisy scenario were 0.583 and 0.504$)$.

Our main result is that our AGENTS behaved "faithfully" toward their principals. By this we mean that they acted in no way differently from PRINCIPALS, either when acting on their own behalf or when acting for their principals--giving advice that they expected would be followed as if it were for themselves. AGENTS acting as principals behaved effectively the same as PRINCIPALS acting as principals (Wilcoxon Rank-Sum: $\mathrm{p}=0.99$ for MAP; $\mathrm{p}=0.81$ for gamble; $\mathrm{p}=0.96$ for betrayal aversion). Similarly, AGENTS acting as agents behaved virtually the same as PRINCIPALS acting as principals (Wilcoxon Rank-Sum: $\mathrm{p}=0.90$ for MAP; $\mathrm{p}=0.37$ for gamble; $\mathrm{p}=0.72$ for betrayal aversion). And AGENTS behaved the same whether they acted as principals or as agents (Wilcoxon Rank-Sum: $\mathrm{p}=0.94$ for MAP; $\mathrm{p}=0.56$ for gamble; $\mathrm{p}=0.64$ for betrayal aversion).

In short, in our data, the actions of principals and agents were strongly in accord. The implication is that, under our realistically framed business scenario with aligned incentives, principals could rely on agents to act as they themselves would act. Importantly, we note that this is not necessarily a praiseworthy accomplishment for our

However, the standard deviation would increase because agents would have to guess what the average principal would do. In fact, the standard deviation of all three groups of decision makers were remarkably similar. 
agents. Indeed, there is a much less optimistic interpretation: agents did not advise against their principals' extreme levels of betrayal and risk aversion despite their duty to serve their principals' interests. In a broad range of situations, such as arranging mergers or other major transactions (the subject of our scenario), AGENTS will usually have much more experience than PRINCIPALS. Moreover, they should have the capacity to approach decisions subject to less cognitive bias. Therefore, we might have expected our AGENTS to advise decisions that reflect less risk aversion, and certainly less betrayal aversion than our PRINCIPALS. Another interpretation of our result here would be that our AGENTS know that the PRINCIPALS should choose differently, but are unwilling or afraid to differ from them and simply parrot back what they think PRINCIPALS want to hear - a frequent criticism of consultants, as observed, e.g., by Shapiro et al. (1993).

\subsection{Final observations and future research}

Our findings identify a number of issues for future study. In gambling Scenario 3, we see clusters of subjects at the $50 \%$ cutoff or just above, whereas many fewer subjects replied with a number just below 50\% (See Figure 2). This suggests a major psychological difference between accepting a payoff with just below a 50\% chance, and one at least equal to that. This is an intuitively plausible behavioral bias that we believe has not yet been identified in the literature. Thus, we would expect people to pay more for going from a $49 \%$ to a $52 \%$ chance of winning a prize than they would to go from $46 \%$ to $49 \%$ or from $52 \%$ to $55 \%$. If true, such a result would have applications in several domains, such as marketing and medicine. 
Figure 2. Frequency of answers to the risky gamble (only showing values between 0.4 and 0.6)

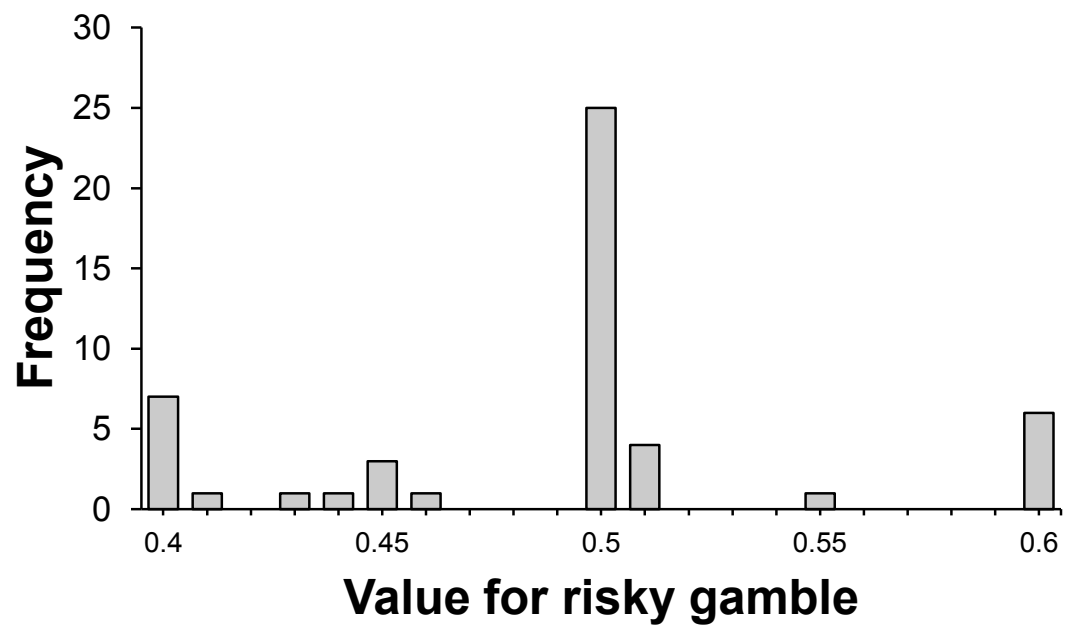

Forty out of 126 subjects who answered this question (or about 27\%) chose to betray. This percentage is almost identical to the percentage betraying in Switzerland and the United States, the two developed Western countries in the study by Bohnet et al. (2010). Coincidentally, it is also extremely close to the percentage that breaks even in expected payoff (29\%).

The subjects who, acting for Daisy, chose to betray did not behave any differently than those who remained loyal to ADC. They had neither higher MAPs in the betrayal scenario $(\mathrm{p}=0.30)$ nor higher MAPs in the gamble $(\mathrm{p}=0.73)$, and they were not more betrayal-averse $(\mathrm{p}=0.61)$. This result is somewhat surprising, since we might have expected betrayers to be less betrayal-averse because they have a higher expectation for the betrayal probability (a finding in Bohnet et al. 2010), or because they find betrayal less unacceptable. As mentioned in an earlier footnote, this could also be caused by the difference in definition of betrayal aversion here and in Bohnet and Zeckhauser (2004), where in the latter subjects played a risky dictator game where the outcome of the economic risk task affected a third party instead of an economic risk taking task. Thus we may confound social preferences and betrayal aversion in our study. However Bohnet and Zeckhauser (2004) found little evidence of a substantial effect of social preferences on betrayal aversion; thus, we do not believe that this is the case. 
Multiple factors could push agents to be less or more betrayal-averse. Presumably, they would be less personally offended by betrayal, which could lead them to be less averse. Moreover, since they advise on large numbers of major business decisions, they might be able to see them more as mere lotteries. This, too, would reduce betrayal aversion. Finally, and amplifying rather than dampening betrayal aversion, agents had to worry about being blamed for a good decision that led to a bad outcome. Blame aversion, a concept not in the literature, deserves future study.

\section{Discussion}

The two major questions addressed in this study are (1) whether we observe significant risk and betrayal aversion among actual seasoned, successful entrepreneurs, i.e., ownermanagers of private businesses having significant enterprise value, as compared to their expert advisors in a realistically framed business scenario and (2) whether risk taking differs according to real-life professional role and/or assigned experimental role (as a principal or as an agent). Understanding the answers to these questions helps shed light not only on the behavior of real-world PRINCIPALS and AGENTS, but also on the relationship between the behavior of individuals in the lab and in their daily lives. Our unique subject pool provided us a valuable opportunity to analyze these questions. We stress that our setup allowed us to explore the decision making of AGENTS in detail, since we could see how their behavior differed across roles and compared to PRINCIPALS. Before presenting our results, we should issue two cautions. First, this study involved many more AGENTS than PRINCIPALS. Second, we believe that the PRINCIPALS were a more highly selected group, representing individuals who had achieved extraordinary success. These two factors, among others, make it important to test our findings further.

Both PRINCIPALS and AGENTS exhibited high levels of risk aversion and betrayal aversion. Thus, our subjects were not qualitatively different in this regard from subjects in past studies, despite their extra real-world experience in similar scenarios. This suggests that significant risk aversion, even over small monetary amounts, is found in 
individuals accustomed to making monetarily consequential decisions (including those significantly affecting the enterprise value of their companies), even when they are deciding in familiar circumstances. Thus, such extreme aversions are not a characteristic merely found in undergraduates making lottery decisions, the traditional fare of experiments on monetary gambles. This finding is reassuring about the relevance of laboratory experiments using students. A conjecture deserving future research, deriving from the experience of Bigelow with large numbers of entrepreneurs, is that entrepreneurs are willing to take risks in their own domain, but shun other risks, a finding that would be consistent with some of the literature cited above (e.g., Holm et al. 2013 who find no difference in economic risk taking between entrepreneurs and others, but that entrepreneurs are more willing to take social risks).

We further observed no differences in levels of these traits according to profession or to role as a principal or an agent. We thus find evidence in support of faithful agents: the agents in our sample could be trusted to represent their principals' interests well. This result suggests that there might not be any decision-making differences between individuals who self-select into AGENT versus PRINCIPAL roles, that spending a career as an AGENT might not influence preferences, and that AGENTS may have self-serving reasons (such as blame aversion) for recommending decisions that differ from those of their PRINCIPALS, at least in the domains that we have explored. The complementary downside observation is that our AGENTS do not appear to be "correcting" in the sense that they are not advising against excessive risk aversion on the part of PRINCIPALS. Agents are surely technical experts, say in evaluating business strategy or analyzing financial statements, but they do not appear to be both able and willing to provide coldly objective advice on major business decisions that may be contrary to the inclinations of their principals (even when such advice would be in their clients' best interest), at least in the domains that we have explored here. Such reluctance by agents may be more surprising given that they were much better educated than our principals $(72 \%$ of AGENTS had graduate degrees, compared to $44 \%$ of PRINCIPALS), and presumably had broader experience with the Daisy-ADC-type business decision. If this inability or reluctance is confirmed in future studies, it should reduce our assessment of the value of hired expertise. Finally, note that our results contrast with the standard assumption in 
moral-hazard models, the assumption that the principal is risk-neutral and the agent is risk-averse.

Our setup does not allow us to distinguish whether AGENTS embraced the preferences of the PRINCIPALS or if they simply had the same preferences as PRINCIPALS. Given that AGENTS acted the same in both roles, though, we are inclined to believe the former is the more likely interpretation. We also note that under either interpretation, the logical extrapolation to the real world is that AGENTS will appear to act faithfully.

Another potential challenge to our results could be that, while PRINCIPALS and AGENTS might in fact differ in their decision-making patterns, our experiment only reported on situations in which they do not. ${ }^{8}$ In other words, our experiment may be a poor proxy for the real world contexts in which PRINCIPALS and AGENTS actually do make decisions. We think this is unlikely for two reasons. First, our sample consisted of real-world PRINCIPALS and AGENTS; and thus our subjects were the individuals we are actually interested in, and not, for example, undergraduates posing as business leaders. Second, our questions were specifically designed to mimic actual business scenarios. (Our main scenario was crafted with the help of seasoned business professionals.) To assess how well this study's results generalize future experiments should be conducted with business professionals as subjects in real-world scenarios calling for decisions. Moreover, cross-cultural versions of our experiment merit exploration, since both risk perception and betrayal aversion have been shown to vary across cultures (e.g., Weber and Hsee 1998; Bohnet et al. 2008). Another interesting extension would examine risk taking within a pool of real world entrepreneurs and their agents, but where the risk is extended to others, as in Bolton and Ockenfels (2010). Often times, the decision making of entrepreneurs and agents will bear consequences on the outcomes of others they care about.

The subjects in this study were individuals who chose to become an entrepreneur or agent and who have had good success in that role. Thus, we cannot disentangle these two factors in their effects on our subjects decision making. It could be the case that

\footnotetext{
${ }^{8}$ It is also the case that risk preferences are not always stable across eliciation methods (see, e.g., Anderson and Mellor 2009).
} 
individuals in general that become entrepreneurs are less risk averse than the general population, but that successful ones are more risk averse, as suggested by Hvide and Panos (2012). Thus it would be interesting to also explore unsuccessful entrepreneurs and agents in a future study. Finally, future studies on entrepreneurs and agents could look at more types of decision making under uncertainty. For example, they could investigate ambiguity aversion as Holm et al. (2013) do when comparing entrepreneurs and other individuals, or seek to disentangle risk and time preferences. ${ }^{9}$

The most surprising finding in our study was the extraordinary concordance between the choices of PRINCIPALS and AGENTS in both the ADC-Daisy betrayal scenario and the gamble, indeed whether AGENTS were acting as principals or agents. That leads to the opening question for philosophical discussion: Should we take reassurance because AGENTS were faithful and consistent in their actions for others and themselves, or should we be discouraged because AGENTS did not counterbalance their PRINCIPALS' high levels of betrayal aversion and risk aversion?

\section{References}

Anderson, L.R., \& Mellor, J.M. (2009). Are risk preferences stable? Comparing an experimental measure with a validated survey-based measure. Journal of Risk and Uncertainty, 39(2), 137-160.

Andreoni, J., \& Sprenger, C. (2012). Risk preferences are not time preferences. American Economic Review, 102(7), 2257-2276.

Berg, J., Dickhaut, J., \& McCabe, K. (1995). Trust, reciprocity, and social history. Games and Economic Behavior, 10(1), 122-142.

Bohnet, I., Herrmann, B., \& Zeckhauser, R.J. (2010). Trust and the reference points for trustworthiness in Gulf and Western countries. Quarterly Journal of Economics, 125(2), 811-828.

Bohnet, I., Greig, F., Herrmann, B., \& Zeckhauser, R.J. (2008). Betrayal aversion: Evidence from Brazil, China, Oman, Switzerland, Turkey, and the United States. American Economic Review, 98(1), 294-310.

\footnotetext{
${ }^{9}$ See, e.g., Coble and Lusk (2010) and Andreoni and Sprenger (2012) for experimental studies distinguishing between risk and time preferences.
} 
Bohnet, I., \& Zeckhauser, R.J. (2004). Trust, risk, and betrayal. Journal of Economic Behavior \& Organization, 55(4), 467-484.

Bolton, G.E., \& Ockenfels, A. (2010). Betrayal aversion: Evidence from Brazil, China, Oman, Switzerland, Turkey, and the United States: Comment. American Economic Review, 100(1), 628-33.

Brockhaus, R.H., Sr. (1980). Risk taking propensity of entrepreneurs. The Academy of Management Journal, 23(3), 509-520.

Chakravarty, S., Harrison, G.W., Haruvy, E.E., \& m, E.E. (2009). Are you risk averse over other people's money? Working Paper, University of Central Florida.

Coble, K.H., \& Lusk, J.L. (2010). At the nexus of risk and time preferences: An Experimental Investigation. Journal of Risk and Uncertainty, 41(1), 67-79.

Daruvala, D. (2007). Gender, risk, and stereotypes. Journal of Risk and Uncertainty, $35(3), 265-283$.

Dohmen, T., Falk, A., Huffman, D., Sunde, U., Schupp, J., \& Wagner, G.G. (2011). Individual risk attitudes: Measurement, determinants and behavioral consequences. Journal of the European Economic Association, 9(3), 522-550.

Elston, J.A., Harrison, G.W., Rutström, E.E. (2006). Experimental economics, entrepreneurs and the entry decision. Working Paper 6, Economics Department, University of Central Florida, Orlando.

Grossman, S.J., \& Hart, O.D. (1983). An analysis of the principal-agent problem. Econometrica, 51(1), 7-45.

Holm, H.J., Opper, S., \& Nee, V. (2013). Entrepreneurs under Uncertainty: An economic experiment. Management Science, in press.

Hvide, H., \& Panos, G.A. (2012). Risk tolerance and entrepreneurship. SSRN Working Paper.

Knight, F., Uncertainty, and Profit. Boston: Houghton Mifflin, 1921.

Macko, A., \& Tyszka, T. (2009). Entrepreneurship and risk taking. Applied Psychology, 58(3), 469-487.

Schubert, R., Brown, M., Gysler, M., \& Brachinger, H.W. (1999). Financial decisionmaking: Are women really more risk-averse? American Economic Review, 89(2), 381385 . 
Schumpeter, J.A. (1934). The Theory of Economic Development. Urbana-Champaign: University of Illinois.

Shane, S.A. (2003). A General Theory of Entrepreneurship: The Individual-Opportunity Nexus, Northampton, MA: Edward Elgar.

Shapiro, E., Eccles, R., \& Soske, T. (1993). Consulting: Has the solution become part of the problem? Sloan Management Review, 34(4), 89-95.

Stewart, W.H. Jr., \& Roth, P.L. (2001). Risk propensity differences between entrepreneurs and managers: A meta-analytic review. Journal of Applied Psychology, 86(1), 145-153.

Stiglitz, J.E. (1987). Principal and agent. The New Palgrave: A Dictionary of Economics, v. 3, 966-71.

Weber, E.U., \& Hsee, C. (1998). Cross-cultural differences in risk perception, but crosscultural similarities in attitudes towards perceived risk. Management Science, 44(9), 1205-1217.

Wu, B., \& Knott, A.M. (2006). Entrepreneurial risk and market entry. Management Science, 52(9), 1315-1330. 


\section{Appendix}

\section{Instructions}

Below are sample instructions from one of the conditions (AGENT acting as a principal) and the risky gamble:

\section{$\underline{\text { Scenario } 1}$}

You are a long-time consultant to Randy, the CEO and sole owner of the Advanced Devices Corporation (ADC), which makes state-of-the-art components for a variety of hand-held electronic products. You advise them on business deals. Randy has recently come to you with an important decision. His problem is described below. Randy has asked you whether ADC should ACCEPT or DECLINE this proposal from Daisy.

ADC's most profitable component is incorporated into the DaisyStar1, a first-generation product of The Daisy Corporation (Daisy). Daisy, a firm roughly the size of ADC, is a respected producer and marketer of electronic products. Your client Randy has exclusive production rights for the critical component of DaisyStarl. Currently, ADC and Daisy each make $\$ 10$ million from this product.

Daisy recently asked Randy to develop the major component for a significantly improved second-generation product called DaisyStar2. That component would require the use of an innovative technology, T, a technology in which ADC is the world leader. Randy is $100 \%$ confident that he could develop this component, and that no other firm could do so.

If Randy ACCEPTS the proposal, Daisy will cover all his engineering costs for the new component, and give his firm a significant incentive payment. If Randy also gets the contract to produce the DaisyStar2, his future profits from DaisyStar1 and DaisyStar2 and the incentive payment would increase significantly to $\$ 15$ million. The Daisy Corporation would also make $\$ 15$ million from these products.

Randy's concern is that Daisy would not engage him for the production phase of the DaisyStar2 component, but rather would go to China, where there are a number of firms that can effectively employ technology $\mathrm{T}$ at a lower cost, though only Randy could innovate with it to develop this product.

Should your client Randy develop technology T for the DaisyStar2 and receive the incentive payment, but Daisy goes to China for production, his profits would fall to $\$ 8$ million. This is because DaisyStar2 would cut into the sales for DaisyStar1. Daisy would save significant monies from China production, and would make \$22 million.

When your client raised this issue with Daisy, it took pains to point out that Randy's current relationship and the fact he developed the new component would put him on the 
inside track for production of the innovative component for the DaisyStar2. In short, it offered reassuring words on the production contract, but was unwilling to make any firm commitment.

Here is the situation in tabular form:

\begin{tabular}{|l|c|c|}
\cline { 3 - 3 } \multicolumn{2}{c|}{} & \multicolumn{2}{|c|}{$\begin{array}{c}\text { Profits to } \\
\text { ADC (Your client } \\
\text { Randy) }\end{array}$} & Daisy \\
\hline $\begin{array}{l}\text { Your client Randy } \\
\text { DECLINES, }\end{array}$ & \$10 million & \$10 million \\
$\begin{array}{l}\text { Only DaisyStar1 } \\
\text { remains in the } \\
\text { market }\end{array}$ & & \\
\hline
\end{tabular}

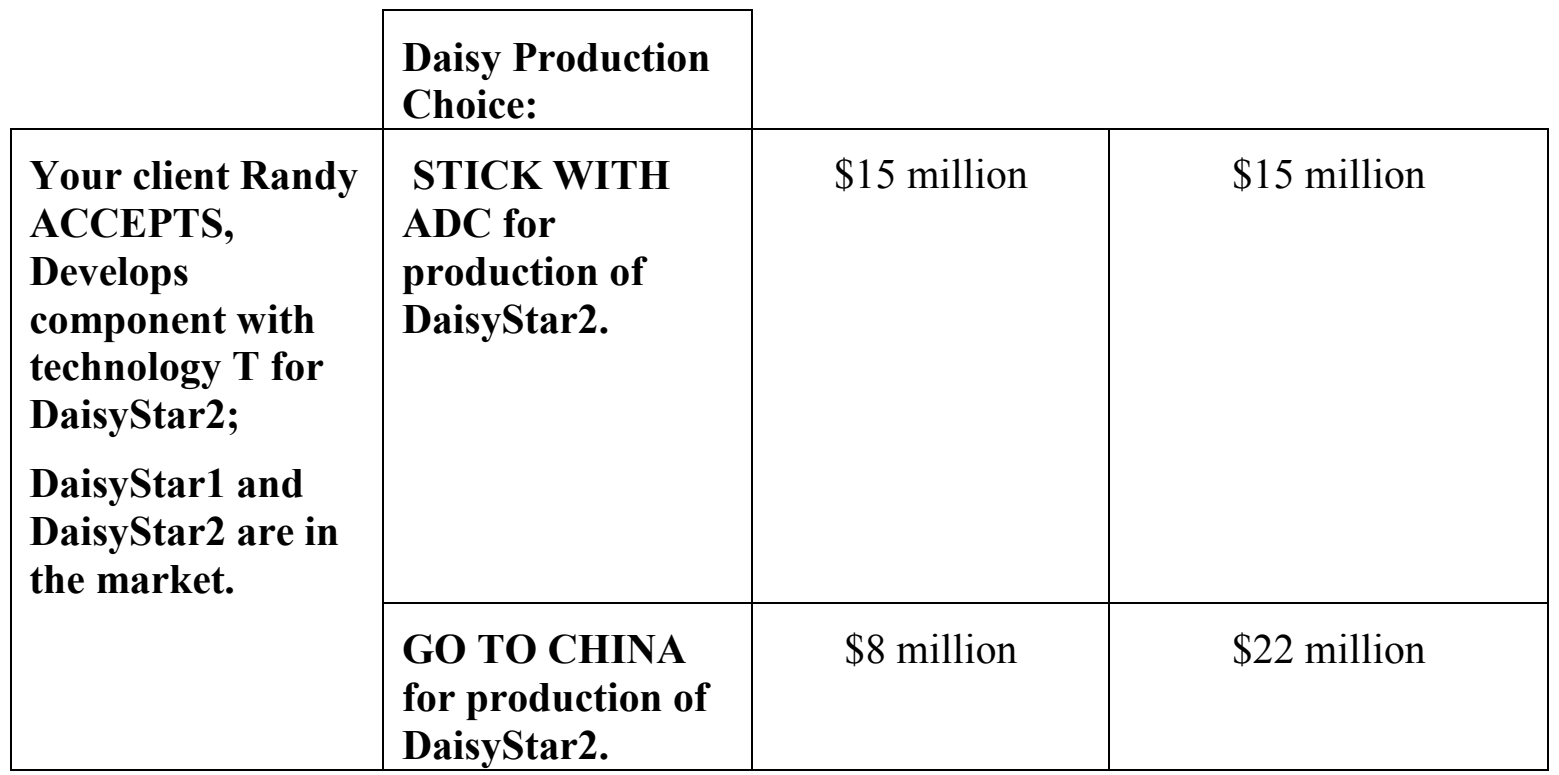

For the purposes of this decision, assume that these dollar values capture all monetary benefits from the alternative outcomes, such as improved knowledge of technology $T$, better relations with Daisy, etc.

Your client Randy must now decide whether to DECLINE or ACCEPT. You expect that Randy will follow your advice.

Your decision to recommend DECLINE or ACCEPT should depend on how likely Daisy is to stick with ADC (Randy) for production. We will select another participant at random to play the part of Daisy in conjunction with you. All participants in this experiment are professionals who have had business contact with The Bigelow Company. 
You can base your decision to recommend DECLINE or ACCEPT on the fraction of Daisy players choosing STICK WITH ADC (Randy). You do not, however, know the decision of the particular person with whom you will be matched.

\begin{tabular}{|l|l|}
\hline Your Question: & $\begin{array}{l}\text { You choose to recommend ACCEPT if at least X\% of Daisy Players } \\
\text { choose STICK WITH ADC for production, otherwise you recommend } \\
\text { DECLINE. } \\
\text { WHAT IS YOUR VALUE OF X\%? }\end{array}$ \\
\hline Rationale: & $\begin{array}{l}\text { If at least X\% of Daisy Players choose to STICK WITH ADC, you } \\
\text { recommend ACCEPT and will play against a random Daisy Player. }\end{array}$ \\
& $\begin{array}{l}\text { If fewer than X\% of Daisy Players choose to STICK WITH ADC, you } \\
\text { recommend DECLINE. }\end{array}$ \\
\hline
\end{tabular}

Remember, you are assigned to interact with a random individual among those assigned to play the role of Daisy.

For participating in this study, both you as Randy's advisor and the player in the role of Daisy will receive $\$ 1$ for each $\$ 1$ million received by your respective companies in the scenario.

Thank you for your answers to Scenarios 1 and 2. We now want you to make a decision in a completely different context.

\section{Scenario 3}

You have to choose one of two alternatives, $\mathbf{A}$ or $\mathbf{B}$.

A gives you a payoff of $\$ 100$ for sure.

B gives you a chance outcome: With probability p you will get $\$ 150$; with probability 1-p you will get $\$ 80$.

Payoff Table

\begin{tabular}{|l|l|l|l|}
\hline You choose & Nature of choice & Probability & Your earnings \\
\hline A & Certainty & 1 & $\$ 100$ \\
\hline B & Lottery & $p$ & $\$ 150$ \\
& & $1-\mathrm{p}$ & $\$ 80$ \\
\hline
\end{tabular}

The payoff table shows this situation:

If you choose $\mathbf{A}$, you will get $\$ 100$.

If you choose $\mathbf{B}$, you will get $\$ 150$ with probability p. You will get $\$ 80$ with probability 1-p. 
Note. We have not told you the value of $\mathrm{p}$. But like any probability, it must lie between 0 and 1 . The value of your $\mathrm{p}$ will be picked randomly, with all values such as $.05, .50$ and .95 being equally likely. Your decision will have no effect on the value of $\mathrm{p}$ picked for you.

KEY QUESTION: How large would p have to be for you to pick Lottery B over Certainty A? YOUR ANSWER: $I$ choose $B$, if $p$ is at least:

Slider: [0------------------------------------1]

\section{Summary statistics}

All the following is based on respondents' self reported information. We first report aggregate summary statistics before breaking our sample down into AGENTS and PRINCIPALS. Our sample was 73.4\% male and 8\% female (N.B. percentages are less than $100 \%$ since some did not report). 27\% had a Bachelor's degree; $20 \%$ had an MBA; $16 \%$ had a JD; $17 \%$ had some other form of graduate degree; $3 \%$ had a CPA; $2 \%$ attended some college; and $1 \%$ had vocational training. Occupations were reported as Accountant (4\%), Attorney (13\%), Commercial Lender/Banker (6\%), Consultant (16\%), Insurance $(2 \%)$, Wealth Manager $(6 \%)$, or Other $(17 \%)$. Finally, self-reported age was by five year blocks; the histogram below shows the corresponding range of reports. 


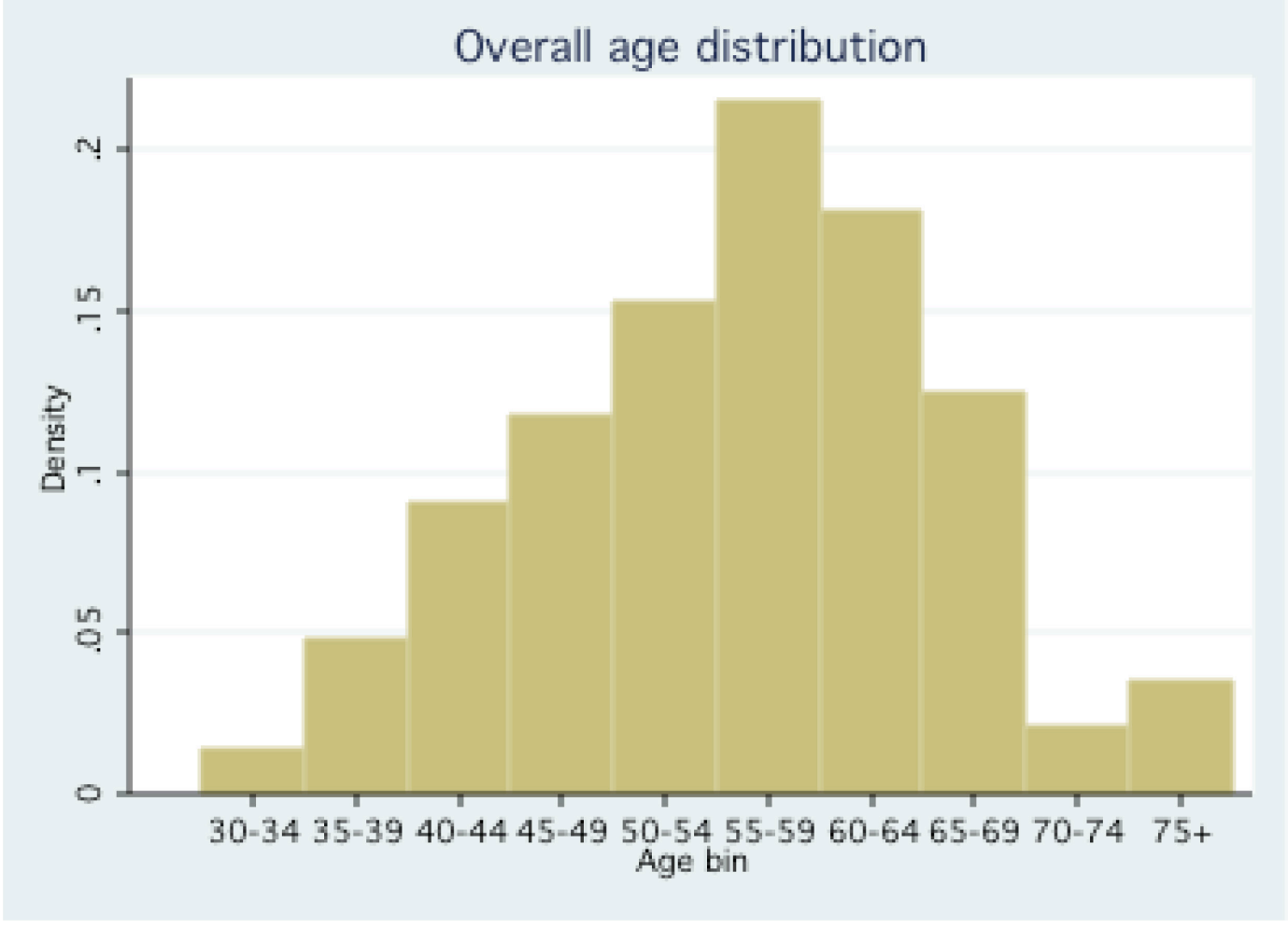

Figure A1. Histogram of age distribution for our entire sample.

We now report the same summary statistics for AGENTS and PRINCIPALS (we report numbers instead of percentages here given that some cells have few people in them). We had 13 female and 94 male AGENTS, whereas we had only 1 female and 33 male PRINCIPALS. Amongst AGENTS, 34 had an MBA, 30 had a Bachelor's, 27 had JD's, 15 had another graduate degree, 5 had CPA's, and 2 attended college; amongst PRINCIPALS, 16 had a Bachelor's, 15 had a graduate degree, 2 attended college, and 1 had vocational training. Occupation was only asked to AGENTS, so the numbers presented above apply to AGENTS only. Below we plot the AGENTS' and PRINCIPALS' age distributions. We note that AGENTS tended to be a little older than the PRINCIPALS. 


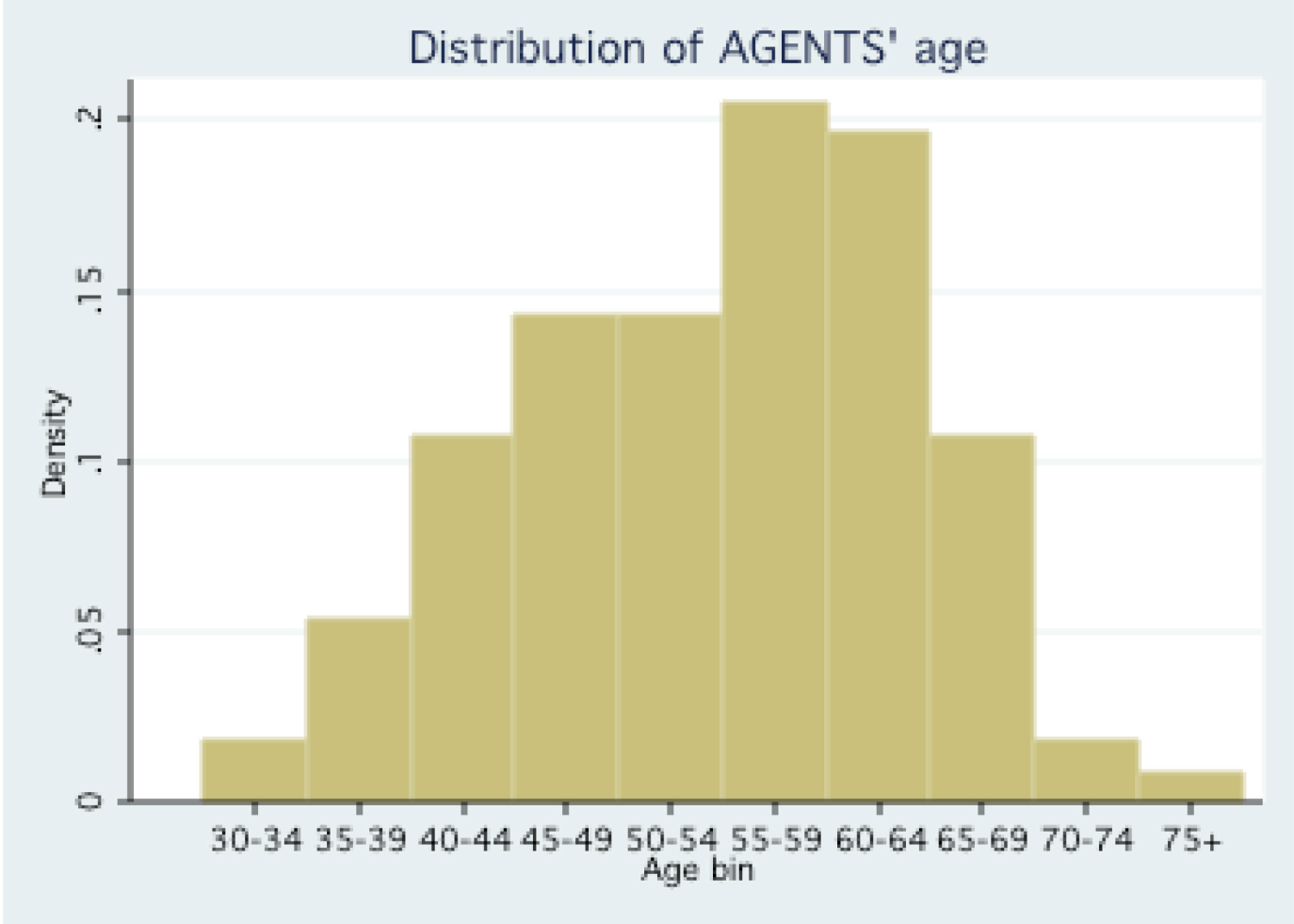

Figure A2. AGENTS' age distribution.

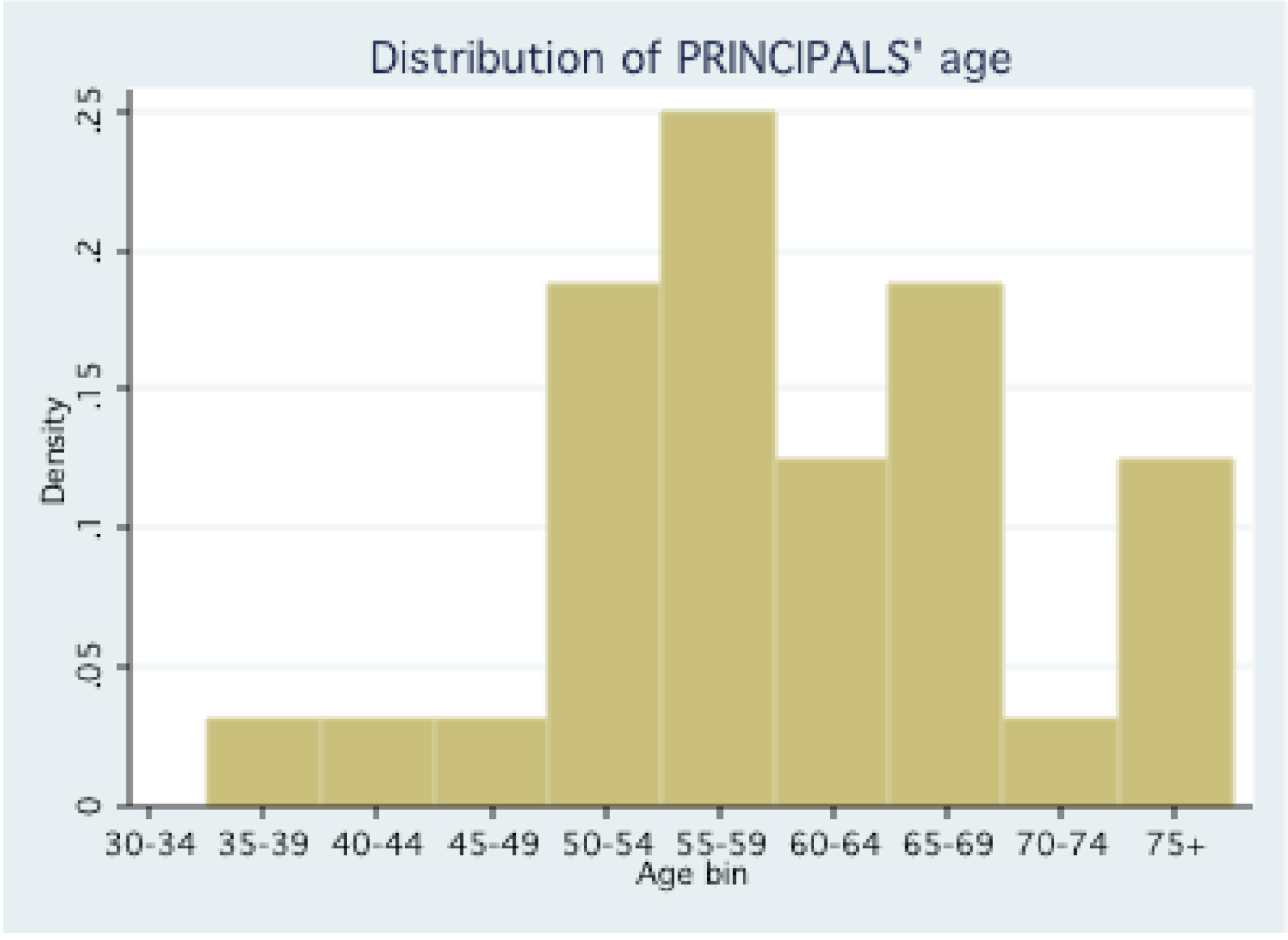

Figure A3. PRINCIPALS' age distribution. 


\section{Sample email}

\section{Example of an email that was sent to recruit participants. (Individuals who did not answer were sent occasional followup emails when the survey was still available.)}

Kimberly A. Goodman

$\begin{array}{ll}\text { From: } & \text { Kimberly A. Goodman <kgoodman@bigelowco.com> } \\ \text { Sent: } & \text { Wednesday, March 28, 2012 9:13 AM } \\ \text { To: } & \text { Kimberly A. Goodman } \\ \text { Subject: } & \text { Entrepreneur Decision Making Survey }\end{array}$

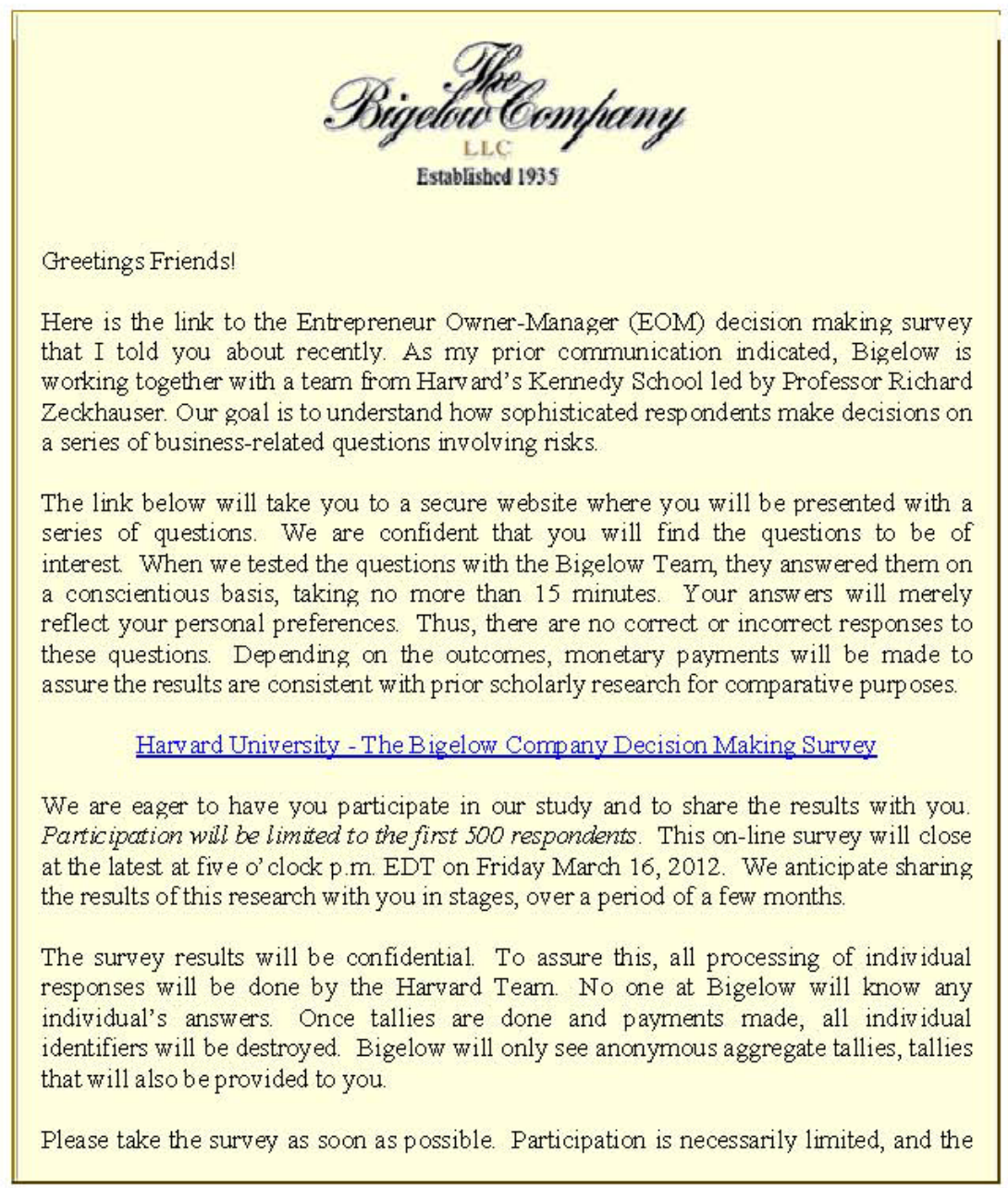


time window is not long.

We are grateful to you for participating in this interesting study.

Sincerely,

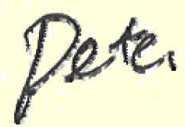

Peter R. Worrell

The Bigelow Company LLC www.bigelowco.com

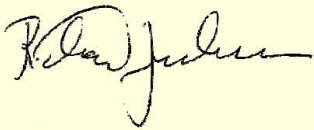

Richard J. Zeckhauser

Frank P. Ramsey Professor

Kennedy School

Harvard University

Securities transactions executed through Bigelow Capital Securities LLC, a registered broker dealer. Member FINRA/SIPC.

Confidentiality Disclaimer: This electronic transmission may contain confidential information that may be privileged, confidential or exempt from disclosure under law, and is for the sole use of the individual to whom it is addressed. If you are not the intended recipient of this email, you are hereby notified that any other dissemination, distribution or copying of this transmission is strictly prohibited. If you receive this message in error, please destroy the attached message (and all attached documents) and notify the sender. The Bigelow Company is required to keep a record of all e-mail communications through its networks.

Thank you for your cooperation.

This message was sent to kgoodman@bigelowco.com from:

The Bigelow Company LLC | One Harbour Place | Portsmouth, NH 03801

Email Marketing by

'iContact

Unsubscribe 